\title{
Impact of Drug-Based Treatment for Osteoporosis on Pain and Parameters of Physical Fitness - A Clinical Pilot Study
}

\author{
Guido Schröder ${ }^{*}$, Raimond Boldt ${ }^{1}$, Anne Hornung ${ }^{2}$, Verena Blaas ${ }^{3}$, Ulrike Voßmann ${ }^{1}$ and Hans-Christof Schober ${ }^{1}$ \\ ${ }^{1}$ Clinic of Internal Medicine, Klinikum Südstadt Rostock, Rostock, Germany \\ 2Institute for Biostatistics and Informatics in Medicine and Ageing Research, University of Rostock, Rostock, Germany \\ ${ }^{3}$ Institute for Forensic Medicine, University Medicine Rostock, St.-Georg-Straße. 108, 18055 Rostock, Germany
}

${ }^{\star}$ Corresponding author: Dr. rer. hum. Guido Schröder, Clinic of Internal Medicine, Klinikum Südstadt Rostock, Rostock, Germany; Phone: +49 (0)381 - 44015000; E-mail: guido.schroeder1@gmx.net

Received: June 29, 2019; Accepted: July 12, 2019; Published: July 16, 2019;

\begin{abstract}
Background: The origin of osteoporosis is attributed to several factors and its prevalence is on the increase. It is one of the principal causes of fractures, morbidity, and chronic pain. Muscle and coordination exercises may help to improve physical performance in everyday life, alleviate pain, and prevent falls. On the other hand, the effect of targeted drug therapy on these parameters is not known yet.
\end{abstract}

Methods: Twenty-five patients with osteoporosis were observed prospectively for 18 months. During this time the patients received targeted drug therapy for the disease. The results of treatment (pre/post) in regard of parameters of physical fitness and pain were analysed.

Results: No changes were noted in respect of torso strength, mobility, and coordination ( $p>0.05)$. The patients' body height was reduced to a significant extent $(\mathrm{p}<0.001$ ), their hand grip strength on the right side was significantly reduced $(\mathrm{p}=0.006)$, and their pain levels were significantly reduced ( $\mathrm{p}=0.001)$. Factors influencing the success of treatment were body weight, height, the administration of teriparatide, and sports.

Conclusions: While pain can be influenced by medication for the treatment of osteoporosis, no effect or even a decline was noted in parameters of physical fitness.

Keywords: Hand grip strength, mobility, osteoporosis, torso strength, pain treatment

\section{Introduction}

Osteoporosis is a systemic disease of bone, marked by reduced bone mass and a disrupted microarchitecture of bone. The result is a greater propensity for fractures and the frequent occurrence of fractures. The latter are associated with pain, limited mobility and quality of life, as well as greater morbidity and mortality [1]. Furthermore, the patient experiences a loss of conditional resources such as muscle strength, endurance, and coordination.

A number of therapy options in terms of drugs and physiotherapy are available for the treatment of this disease. Regular physical exercise alleviates pain, prevents falls, and improves mobility and quality of life [2-4]. Specific medications for osteoporosis, such as bisphosphonates, reduce fracture rates by adhering firmly to bone surfaces and inhibiting the enzyme known as farnesyl pyrophosphate synthase, which is needed in osteoclasts for the formation of the cytoskeleton $[5,6]$. Monoclonal antibodies also contribute significantly to reducing the risk of fractures [7]. The impact of long-term specific drug therapy on the development of motor and coordination skills in the course of the disease has been poorly investigated so far. Especially pain caused by osteoporosis is of paramount importance for many patients. Alleviating such pain by drug therapy would be subjectively interpreted as successful treatment and an improvement in quality of life for many patients; this was the subject of the current prospective study.

\section{Material and Methods}

The aim of the present study is to evaluate the impact of targeted drug therapy on parameters of physical fitness and pain experienced by patients with osteoporosis. Statements about the factors influencing the success of treatment will also be evaluated.

\section{Study Design and Recruitment}

We conducted a prospective single-centre clinical investigation of a treatment group. All probands were informed in detail about the methods, purposes, and risks of the study protocol. Furthermore, they were handed out a copy of their written informed consent. The probands were recruited during the outpatient consultation hours for osteoporosis at the Südstadt Klinikum in Rostock. The recruitment of patients takes 2 years. This made it difficult to predict the required number of patients with regard to the significance of the clinical examination. 


\section{Inclusion and Exclusion Criteria}

Inclusion criteria for the clinical study were the presence of proven osteoporosis requiring treatment in patients with pathological bone densitometry values and the availability of X-rays of the thoracic and lumbar spine. At the start of the study, all patients underwent a physical investigation to determine their orthopaedic status, which included the Chair-Rising test (CR test), walking speed (WS), Tandem Stand (TS), Tandem Gait (TG), Hand Grip Strength (HGS), and a guideline-oriented laboratory screening.

Exclusion criteria were all forms of severe heart failure, uncontrolled hypertension, relevant neurological deficits, vestibulopathy, and the need for external care.

\section{Clinical Tests}

\section{Short Physical Performance Battery (SPPB)}

It consists of three tests: tandem stand, walking for 4 meters, and the $\mathrm{CR}$ test $[8,9]$. For each task the patient may achieve a maximum of 4 points. The scores of the three tests are then added. A person may achieve a minimum score of 0 and a maximum score of 12 points. We used the SPPB to measure the function of the lower extremities when performing tasks similar to the activities of daily living. Based on the total score, one can estimate how severely the patient is limited in his/ her daily life. Patients with a final score of 0 to 3 points are strongly impaired, especially when walking a few hundred meters, ascending stairs, and in self-care $[10,8]$. Patients with a final score of 4 to 6 points are moderately impaired, and those with a score from 7 to 9 points are mildly impaired. A patient who achieves a score of 10 to 12 points is minimally impaired or not impaired in his/her daily life.

The patient's balance and coordination were tested with the aid of the tandem stand. Three positions were retained for 10 seconds each: standing with closed feet, semi-tandem stand (the heel of one foot is at the mid-portion of the inside of the other foot), and tandem stand (one foot behind the other). The patient is free to decide which foot is placed in the front.

The walking test measures the time taken to walk 4 meters at normal speed. This task combines the patient's strength and coordination in walking and is therefore a good parameter to assess physical performance capacity [11]. The threshold value for limited mobility is a walking speed of $\leq 0.8$ meters per second [12].

The CR test measures five consecutive cycles of standing up from, and sitting on a chair without armrests, with the patient's arms folded across his/her chest. In general the SPPB is a frequently used instrument that has proved its value not only for the identification and description of probands at the disabled end of the functional spectrum, but also for non-disabled elderly persons [9].

The results constitute a part of the SPPB on the one hand, and provide information about a normal or elevated risk of falls on the other: a score $\leq 10 \mathrm{~s}$ is normal, whereas a score $>10 \mathrm{~s}$ signifies an elevated risk of falling [13].

Figure 1 (Figure 1) shows an example of the CR test (a), the TS (b), and the test of WS (c).

\section{Hand Grip Strength (HGS)}

In addition to the SPPB we measured HGS in kilograms (kg) with a traditional hand grip strength dynamometer. A score of $<27 \mathrm{~kg}$ is considered to indicate limited physical capacity for men, while the cutoff value for women is $16 \mathrm{~kg}$ [12]. The HGS is an efficient and simple method to test overall strength in elderly persons, and has a high and independent predictive power in regard of functional limitations and disabilities $[14,15]$.

\section{Tandem Gait (TG)}

TG: The patient is asked to walk 8 steps in a straight line. The outcome provides additional information about the risk of falling, to the extent that 8 walked steps are considered synonymous with a halved risk of falling in a comparison of age [13].

\section{Pain}

In the present clinical trial we used the Numerical Rating Scale (NRS). The latter is a unidimensional pain scale with 11 grades, with 0 indicating no pain and 10 the most severe imaginable pain. The probands selected the grade that described their perception of pain. The advantages of the NRS are the low error rate of its results and its high acceptance by test persons [16].

\section{Non-Pharmacological Treatment for Osteoporosis}

Calcium

Many postmenopausal women consume too little calcium. Supplementation is therefore useful, also to reduce fracture rates [17]. In the present investigation we tried to achieve a calcium supplementation level of $800 \mathrm{mg}$ daily in order to achieve optimum absorption. After an initial laboratory investigation of retention parameters the patients were given nutritional counselling and advised to consume natural sources of calcium such as milk and cheese instead of food supplements $(500 \mathrm{mg}$ ). The latter was only used in cases of marked deficiency, because the undesirable gastrointestinal effects of taking calcium could reduce the patients' compliance. Furthermore, it has been found that higher doses of calcium may cause kidney stones or myocardial infarction [18].

\section{Cholecalciferol}

The probands were advised to take 20000 IU of vitamin D3 every week. The aim of the treatment was to achieve a serum 25-hydroxyvitamin-D level above $55 \mathrm{nmol} / \mathrm{l}$.

Additionally all probands were given information about a balanced diet with a protein content of $1 \mathrm{~g} / \mathrm{kg}$ daily [5].

\section{Pharmacological Treatment for Osteoporosis}

Bisphosphonates

A variety of bisphosphonates are currently approved for the treatment of postmenopausal osteoporosis. We used the following substances among others:

- Alendronate $10 \mathrm{mg}$ daily or $70 \mathrm{mg}$ weekly taken orally; men with osteoporosis were given $10 \mathrm{mg}$ daily. 
- Zolendronate $5 \mathrm{mg}$ intravenously once every year in postmenopausal women and men with an elevated risk of fractures, including those with a recent fracture due to mild trauma, and for the treatment of osteoporosis in association with long-term systemic glucocorticoid therapy in both genders.
- Ibandronate $150 \mathrm{mg}$ a month taken orally, or $3 \mathrm{mg}$ as an intravenous injection every 3 months in postmenopausal women with an elevated risk of fractures [19].

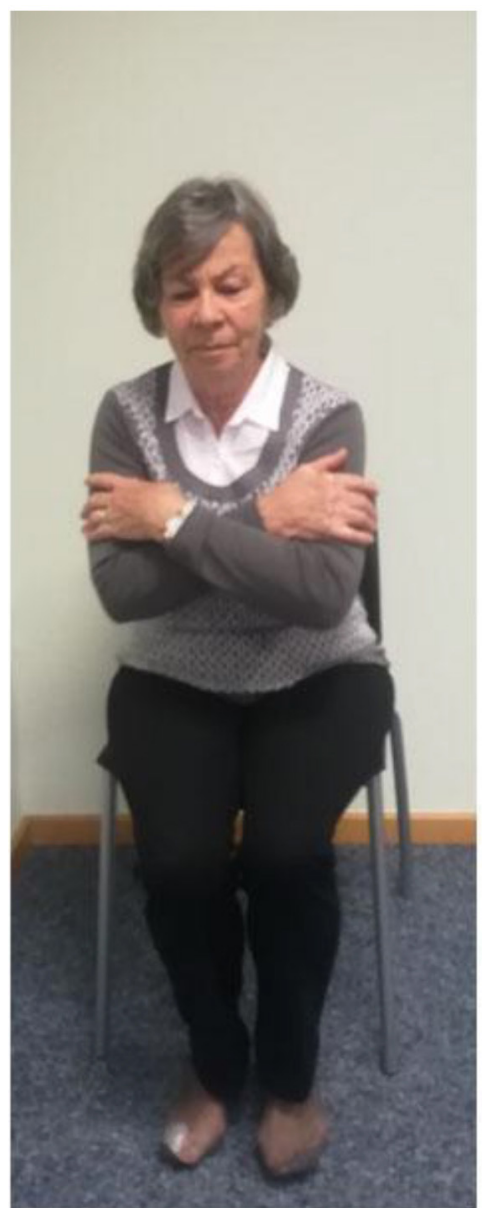

a

CR test (a), TS (b), WS (c)

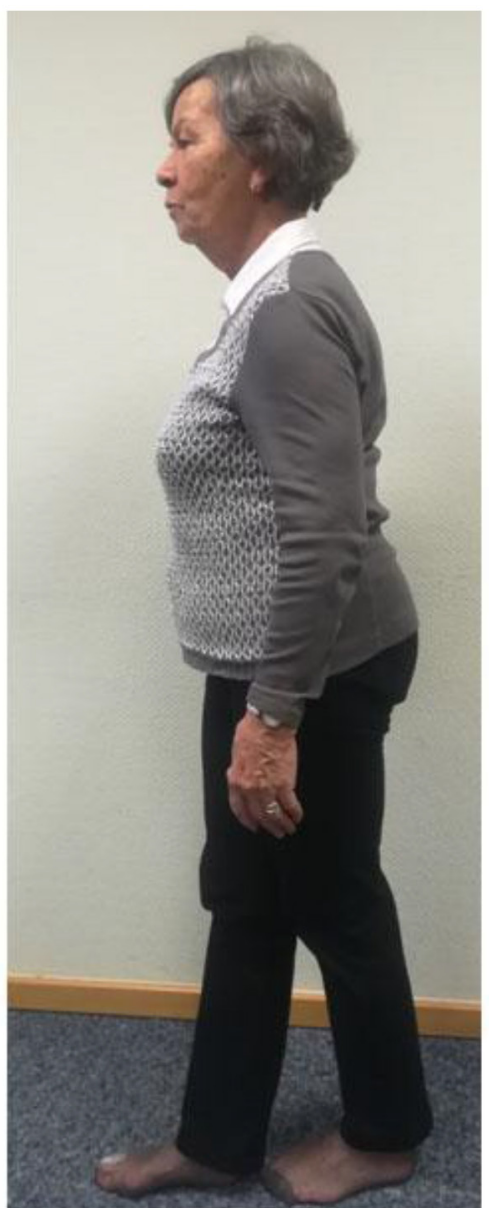

$\mathrm{b}$

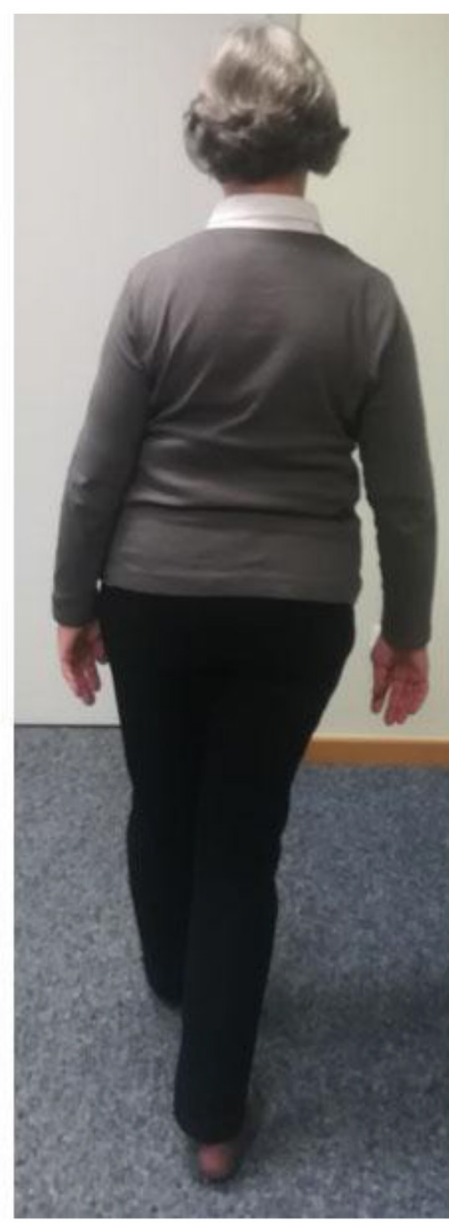

c

Figure 1. Exemplary tests of strength, coordination and mobility

\section{Denosumab}

This is a monoclonal antibody against the receptor activator of the nuclear factor-kappa B ligand (RANKL), an important regulator of the development and activity of osteoclasts. It is also approved for the treatment of postmenopausal osteoporosis and for men with an elevated risk of fractures. In the present study denosumab was administered - in persons with the appropriate indication - as a subcutaneous injection at a dose of $60 \mathrm{mg}$ every 6 months [19].

\section{Teriparatide}

Several cell pathways in the osteoblast are activated by teriparatide, which in turn leads to greater osteoblast recruitment [5]. In patients with an appropriate indication, teriparatide was administered at a dose of 20 to $40 \mathrm{mg}$ daily.

\section{Strontiumranelate}

The distrontium saltknown as strontiumranelateconsists of two atoms of stable strontium and the organic portion, which is ranelic acid. It improves osteoblastic cell replication and enhances collagen synthesis. Simultaneously it reduces the differentiation of osteoclasts and the bone resorption activity of mature osteoclasts in vitro [20]. In patients with the appropriate indication it was given at a dose of 2 g daily.

\section{Testosterone}

Hypogonadism is the most frequent cause of osteoporosis in men. In this setting it may be useful to administer the male sexual hormone testosterone as a gel. 


\section{Statistics}

The collected data were analysed using the statistical software packet SPSS, Version 23.0 (SPSS Inc., Chicago, USA). In a first step we performed a descriptive evaluation. The quantitative characteristics were described using means $[\mathrm{MW}]$, Standard Deviation (SD), minimum and maximum values, and the number of available observations; these were shown with the interval of means \pm standard deviation. For the qualitative characteristics we mentioned absolute and percentage frequencies of the individual grades of severity.

Depending on the result of the Shapiro-Wilk tests on normal distribution, we used the dependent t-test to evaluate changes in the respective parameters between the various time points of measurement, and Wilcoxon's rank sum test. To test qualitative characteristics and analyse categorical frequencies we used the $\mathrm{Chi}^{2}$ test. We then calculated the effect size from the quotient of the test value $(\mathrm{z})$ and the square root of the number of probands (n). A resulting value below 0.3 was rated as a weak effect, a value between 0.3 and 0.5 as a moderately strong effect, and a value higher than 0.5 as a strong effect. The effect size of Cohen's D was determined from the quotient of the mean value difference and the standard deviation (SD). A resulting value from 0.2 onward was rated weak, a value from 0.5 onward as moderate, and a value beyond 0.8 as a strong effect.

All p-values are the result of two-sided statistical tests; the level of significance was set to $\mathrm{p} \leq 0.05$.

\section{Results}

\section{Probands and Baseline Characteristics of the Study Population}

Twenty-five patients with osteoporosis participated in the clinical trial. The patients' age at the start of the investigation was between 48 and 78 years $(65.0 \pm 8.3)$. Twenty-three of 25 probands (92\%) concluded the clinical investigation. NRS values could not be determined for two patients because of the absence of appropriate documentation. Table 1 summarizes the baseline characteristics of the study population.

\section{Height, Body Weight, BMI}

The patients' height at the time point T0 was on average $167.2 \pm 7.7 \mathrm{~cm}$. In the observation period we registered a mean value of $164.5 \pm 8.1 \mathrm{~cm}$, which amounted to a highly significant difference $(p<0.001)$ between the two time points. The change in the patients' BMI was also very significant $(\mathrm{p}=0.008)$. On the other hand, weight did not differ significantly between T0 und T1 ( $\mathrm{p}>0.05)$.

\section{CR test}

With regard to the CR test, at the start of the investigation we noted a mean value of $9.7 \pm 2.3$ seconds. After the conclusion of treatment there was a statistical trend in terms of a deterioration of torso strength $(10.7 \pm 2.7 \mathrm{~s}, \mathrm{p}=0.086)$.

\section{Walking Speed}

WS at the time point T0 was on average $0.9 \pm 0.1 \mathrm{~m} / \mathrm{s}$. At T1 the mean value was $0.9 \pm 0.2 \mathrm{~m} / \mathrm{s}$. The pairwise comparison of means revealed no significant difference $(\mathrm{p}=0.573)$.

Table 2 provides an overview of the above mentioned parameters.

\section{Hand Grip Strength}

HGS on the right side was reduced after drug therapy from $29.6 \pm 9.9 \mathrm{~kg}$ to $27.2 \pm 8.6 \mathrm{~kg}$; the difference was highly significant $(\mathrm{p}=0.006)$. On the left side there was no significant difference $(\mathrm{p}>0.05)$. On the left side HGS was $28.0 \pm 9.8 \mathrm{~kg}$ at the start of treatment and then reduced to $26.5 \pm 8.4 \mathrm{~kg}$.

Figure 2 shows the relative changes in the CR test, WS, and HGS.

\section{Tandem Gait}

On tandem gait the patients were able to walk a minimum of 4 steps and a maximum of 8 steps at the start of treatment. At time point T1 we observed no significant difference in this regard ( $p>0.05)$.

\section{SPPB}

The SPPB values were between 8 and 11 points at the start of the investigation, and $10.2 \pm 1.0$ points on average. A comparison of values at the start of the investigation (T0) and after 18 months of drug treatment for osteoporosis (T1) revealed no significant difference $(10.2 \pm 1.0$ points, $\mathrm{p}=0.776)$.

\section{Pain}

Sixty percent of the study participants said they had occasional pain and $28 \%$ had pain every day. The intensity of pain was moderate (NRS $4.4 \pm 2.9$ ) at the start of the investigation. Pain was primarily described as dulland was mainly experienced in the lumbar spine. Thirty-two percent of patients had persistent pain throughout the day or in the evening. Twenty-eight percent of the patients used painkillers of the WHO category I regularly while $8 \%$ used NSAID. Four percent of patients used phytopharmaceuticals or painkillers of the WHO category II, and $12 \%$ used a combination of treatments. After 18 months of drug treatment for osteoporosis the patients' pain levels on the NRS were reduced on average to $2.6 \pm 2.0$ points; the result was highly significant ( $\mathrm{p}=0.001)$, and the effect was strong $(\mathrm{r}=0.508)$.

Table 3 provides a summary of the results in regard of the above mentioned parameters.

\section{Success of Treatment}

We rated the success of treatment (SOT) on a numerical rating scale from 0 to 10 . An improvement by at least 2 points on the NRS was rated as successful treatment. Eight patients concluded the treatment successfully, whereas 15 patients experienced no success of treatment (NTS). We also determined the corresponding factors that influenced the success of treatment. 
Table 1. Baseline characteristics of the study population $(n=25)$

\begin{tabular}{|c|c|}
\hline General medical history & $\mathbf{M} \pm \mathbf{S D}$ (Min-Max) \\
\hline Gender $\mathrm{m} / \mathrm{f}$ & $3 / 22$ \\
\hline Age (years) & $65.0 \pm 8.3(48-78)$ \\
\hline Height $(\mathrm{cm})$ & $167.2 \pm 7.7(154-181)$ \\
\hline Weight (kg) & $66.4 \pm 11.6(48-95)$ \\
\hline BMI $\left(\mathrm{kg} / \mathrm{m}^{2}\right)$ & $23.7 \pm 3.4(18.7-33.3)$ \\
\hline Bone density (SD) & $-2.7 \pm 0.9$ \\
\hline $\begin{array}{l}\text { Fractures yes/no (\%) } \\
\text { - } \quad \text { Central (\%) } \\
\text { - } \\
\text { - } \\
\text { Peripheral (\%) } \\
\text { Both (\%) }\end{array}$ & $\begin{array}{c}76 / 24 \\
60 \\
4 \\
12\end{array}$ \\
\hline School education 12 years $/<12$ years $(\%)$ & $24 / 76$ \\
\hline Smokers / Non-smokers (\%) & $28 / 72$ \\
\hline \multicolumn{2}{|l|}{ Drugs for osteoporosis } \\
\hline Bisphosphonates (\%) & 68 \\
\hline Monoclonal antibodies (\%) & 16 \\
\hline Recombinant human parathyroid hormone fragment (\%) & 8 \\
\hline Strontiumranelate (\%) & 4 \\
\hline Cholecalciferol (\%) & 72 \\
\hline Calcidiol (\%) & 4 \\
\hline Calcium 500mg (\%) & 4 \\
\hline $\begin{array}{l}\text { Food rich in calcium prior to nutritional counselling } \\
\text { yes/no }(\%)\end{array}$ & $16 / 84$ \\
\hline \multicolumn{2}{|l|}{ History of pain } \\
\hline Back pain yes/no (\%) & $88 / 12$ \\
\hline $\begin{array}{l}\text { Frequency of pain } \\
\text { - } \quad \text { Daily (\%) } \\
\text { - } \quad \text { Occasionally (\%) } \\
\text { - } \quad \text { Never }(\%)\end{array}$ & $\begin{array}{l}28 \\
60 \\
12\end{array}$ \\
\hline $\begin{array}{l}\text { Intensity of pain } \\
\text { - } \quad \text { NRS } 0-10^{(\mathrm{n}=23)}\end{array}$ & $4.4 \pm 2.9(0-9)$ \\
\hline 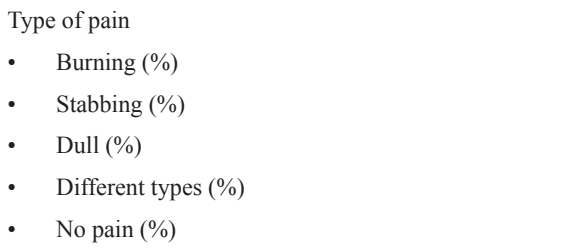 & $\begin{array}{c}8 \\
12 \\
56 \\
12 \\
12\end{array}$ \\
\hline $\begin{array}{ll}\text { Location } \\
\text { - } & \text { Cervical spine (\%) } \\
\text { - } & \text { Thoracic spine (\%) } \\
\text { - } & \text { Lumbar spine (\%) } \\
\text { - } & \text { Entire spine (\%) } \\
\text { - } & \text { No pain }(\%)\end{array}$ & $\begin{array}{c}0 \\
4 \\
56 \\
28 \\
12\end{array}$ \\
\hline $\begin{array}{ll}\text { Time of maximum pain } \\
\text { - } & \text { Morning }(\%) \\
\text { - } & \text { Noon }(\%) \\
\text { - } & \text { Evening }(\%) \\
\text { - } & \text { Night }(\%) \\
\text { - } & \text { Whole day (\%) } \\
\text { - } & \text { No pain }(\%)\end{array}$ & $\begin{array}{c}12 \\
4 \\
32 \\
8 \\
32 \\
12\end{array}$ \\
\hline Regular use of analgesics yes/no (\%) & $28 / 72$ \\
\hline
\end{tabular}

\begin{tabular}{|c|c|}
\hline General medical history & $\mathbf{M} \pm \mathbf{S D}($ Min-Max) \\
\hline 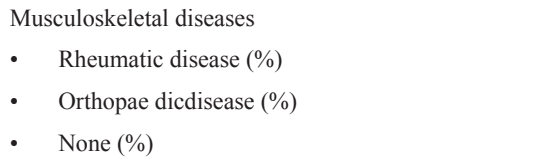 & $\begin{array}{l}20 \\
32 \\
48\end{array}$ \\
\hline $\begin{array}{l}\text { Work situation } \\
\text { - } \quad \text { Labourer (\%) } \\
\text { - } \quad \text { Seeking employment/work (\%) } \\
\text { - } \quad \text { Pensioner (\%) }\end{array}$ & $\begin{array}{c}28 \\
0 \\
72\end{array}$ \\
\hline Activities that challenge the back muscles yes/no (\%) & $32 / 68$ \\
\hline $\begin{array}{ll}\text { Activity profile } \\
\text { - } & \text { Sedentary }(\%) \\
\text { - } & \text { Standing (\%) } \\
\text { - } & \text { Mixed (\%) }\end{array}$ & $\begin{array}{c}32 \\
8 \\
60\end{array}$ \\
\hline Sports yes/no $(\%)$ & $76 / 24$ \\
\hline
\end{tabular}

Data presented as means $\pm \mathrm{SD}$ and percentages

Table 2. Results of parametric tests as percentage changes $(n=25)$

\begin{tabular}{|l|c|c|c|}
\hline \multicolumn{1}{|c|}{ Parameter } & $\begin{array}{c}\text { Observation period } \\
\text { vs. Baseline }\end{array}$ & p-value $^{\dagger}$ & $\begin{array}{c}\text { Effect size, } \\
\text { Cohens d }\end{array}$ \\
\hline Height & $-1.6 \pm 1.8$ & $<0.001$ & $0.869^{* * *}$ \\
\hline Weight & $0.9 \pm 6.0$ & 0.616 & ------- \\
\hline BMI & $4.1 \pm 7.3$ & 0.008 & $0.579^{* *}$ \\
\hline Chair-rising test & $12.3 \pm 27.1$ & 0.086 & ------ \\
\hline Walking test & $3.7 \pm 21.2$ & 0.573 & ------ \\
\hline
\end{tabular}

Data presented as means $\pm \mathrm{SD},{ }^{\dagger} \mathrm{t}$ test against $0, *$ weak, $* *$ moderate, $* * *$ strong

Table 3. Results of the non-parametricsigned rank test $(n=25)$

\begin{tabular}{|l|l|l|}
\hline Parameter & p-value ${ }^{\Theta}$ & Effect size, $\mathbf{r}$ \\
\hline Hand grip strength on the right side & 0.006 & $0.391^{* * *}$ \\
\hline Hand grip strength on the left side & 0.136 & ------- \\
\hline Tandem gait & 0.443 & ------ \\
\hline SPPB & 0.776 & ------ \\
\hline NRS (n=23) & 0.001 & $0.508^{* * *}$ \\
\hline
\end{tabular}

eWilcoxon test, ${ }^{*}$ weak, $* *$ moderate, $* * *$ strong

The two groups differed very significantly in terms of body weight at the start of the investigation [57.4 $\pm 6.8 \mathrm{~kg}$ (SOT) vs. $70.3 \pm 11.2 \mathrm{~kg}$ (NTS), $\mathrm{p}=0.007$, and still differed significantly after the intervention [59.6 $\pm 9.0 \mathrm{~kg}$ (SOT) vs. $69.3 \pm 10.0 \mathrm{~kg}$ (NTS), $\mathrm{p}=0.033$ ]. With regard to height, a statistically significant difference was noted between the two groups [161.9 $\pm 6.8 \mathrm{~cm}$ (SOT) vs. $169.0 \pm 6.6 \mathrm{~cm}$ (NTS), $\mathrm{p}=0.023$ ], which remained significant in the observation period [158.8 \pm $4.4 \mathrm{~cm}$ (SOT) vs. $166.5 \pm 7.9 \mathrm{~cm}$ (NTS), $\mathrm{p}=0.019$ ]. With regard to BMI, at baseline the difference between the two groups revealed a trend towards significance $(\mathrm{p}=0.073)$, which was no longer present after the conclusion of treatment ( $p>0.05$ ). With regard to the prescribed drugs, a difference was only noted between the SOT and NTS groups when they took teriparatide $(\mathrm{p}=0.043)$. As regards sports, a significant difference was noted between the SOT and NTS groups $(\mathrm{p}=0.021)$. 


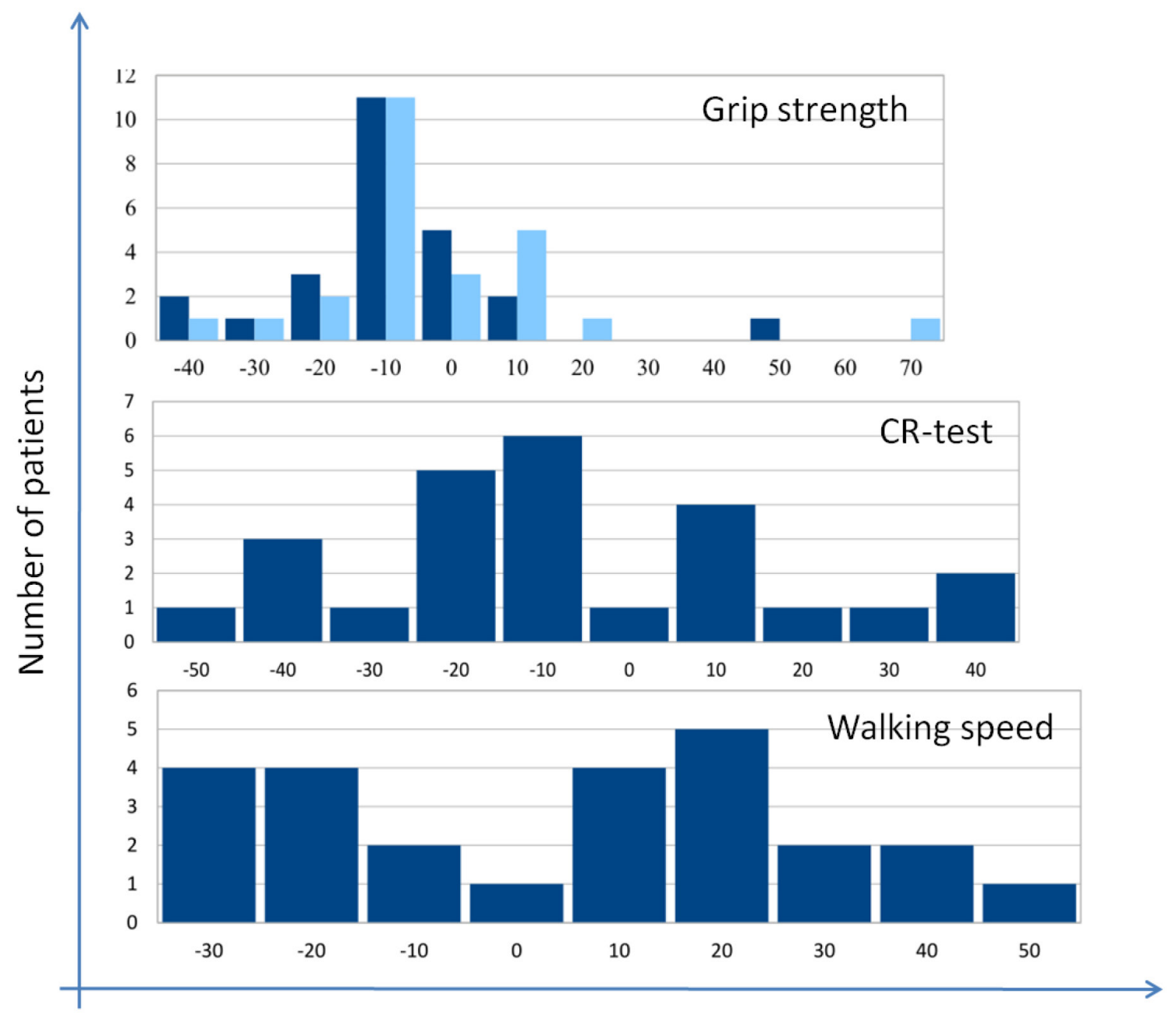

\section{Relative change in percent}

Figure 2. Relative changes in selected parameters of strength and mobility

In contrast, for the CR test, walking speed, new fractures, and food rich in calcium, we registered no significant differences between the individual time points of measurement ( $\mathrm{p}>0.05$ ) (Table 4$)$. The factors influencing the success of treatment are summarized in Table 4.

\section{Discussion}

The present investigation is the first to provide comprehensive data on the effects of 18 months of drug treatment for osteoporosis on parameters of physical fitness and pain. The level of pain could be reduced significantly in the entire group, whereas the parameters of physical fitness remained unchanged or even deteriorated. While the reasons for this change are manifold, we presume that the drug treatment could have influenced the patients' perception of pain. In our investigation, especially teriparatide was found to exert favourable effects. Soen et al. [21] achieved similar results in their investigation of about 2000 patients who took $20 \mu \mathrm{g}$ of teriparatide daily. The mode of action of this drug is not fully investigated yet and calls for further research. One potential mechanism of reducing back pain is reducing the severity as well as the number of new vertebral fractures
[22]. New fractures played a subsidiary role in the present study, especially with regard to the success of treatment. The other drugs that we administered also had an effect on the patients' perception of pain, regardless of the success of treatment. In the present study 68 $\%$ of the probands were given bisphosphonates, which enhance bone density by inhibiting osteoclast activity, and thus markedly suppress bone turnover when used for a long period of time [23]. However, these drugs may also cause an accumulation of micro injuries and thus impair the healing of stress fractures [24]. Despite an increasing quantity of bone, the quality of bone may deteriorate, which may favour bisphosphonate-related proximal femoral fractures among other conditions [25]. However, an animal experiment performed by Naito et al. [26] showed that treatment with alendronate may halt bone resorption and reduce levels of pain mediators. Compared to other bisphosphonates, the unique mechanism of action of minodronate on the inhibition of the $\mathrm{P} 2 \mathrm{X}(2 / 3)$ receptor is advantageous, especially in reducing back pain among patients with osteoporosis [27]. However, in the present investigation we did not use minodronate. It should be noted that patients with osteoporosis benefit from the alleviation of pain in terms of an improvement of their quality of life. 
Table 4. Success of treatment

\begin{tabular}{|c|c|c|c|}
\hline Parameter & $\begin{array}{c}\text { Successful } \\
\text { treatment }^{*} \\
\quad(n=8)\end{array}$ & $\begin{array}{c}\text { No successful } \\
\text { treatment } \\
(n=15)\end{array}$ & p-value \\
\hline Age (years) & $63.3 \pm 8.5$ & $65.1 \pm 8.3$ & $0.625^{\pi}$ \\
\hline \multicolumn{4}{|l|}{ Weight (kg) } \\
\hline Before the intervention & $57.4 \pm 6.8$ & $70.3 \pm 11.2$ & $0.007 \pi$ \\
\hline After the intervention & $59.6 \pm 9.0$ & $69.3 \pm 10.0$ & $0.033^{\pi}$ \\
\hline \multicolumn{4}{|l|}{ Height $(\mathrm{cm})$} \\
\hline Before the intervention & $161.9 \pm 6.8$ & $169.0 \pm 6.6$ & $0.023^{\pi}$ \\
\hline After the intervention & $158.8 \pm 4.4$ & $166.5 \pm 7.9$ & $0.019^{\pi}$ \\
\hline \multicolumn{4}{|l|}{ BMI $\left(\mathrm{kg} / \mathrm{m}^{2}\right)$} \\
\hline Before the intervention & $21.9 \pm 2.0$ & $24.6 \pm 3.8$ & $0.073^{\pi}$ \\
\hline After the intervention & $23.5 \pm 2.9$ & $25.0 \pm 4.1$ & $0.355^{\pi}$ \\
\hline \multicolumn{4}{|l|}{ Chair rising test (s) } \\
\hline Before the intervention & $8.9 \pm 2.3$ & $10.2 \pm 2.2$ & $0.105^{\pi}$ \\
\hline After the intervention & $10.1 \pm 1.8$ & $10.9 \pm 3.1$ & $0.496^{\pi}$ \\
\hline \multicolumn{4}{|l|}{ Walking speed (m/s) } \\
\hline Before the intervention & $0.9 \pm 0.1$ & $0.9 \pm 0.1$ & $0.413^{\pi}$ \\
\hline After the intervention & $0.9 \pm 0.1$ & $0.9 \pm 0.2$ & $0.469^{\pi}$ \\
\hline Smokers yes/no & $3 / 5$ & $4 / 11$ & $0.591^{\mathrm{c}}$ \\
\hline Bisphosphonates yes/no & $7 / 1$ & $8 / 7$ & $0.101^{\mathrm{c}}$ \\
\hline Monoclonal antibodies yes/no & $1 / 7$ & $3 / 12$ & $0.651^{\mathrm{c}}$ \\
\hline $\begin{array}{l}\text { Recombinant human } \\
\text { parathyroid hormone fragment }\end{array}$ & $2 / 6$ & $0 / 15$ & $0.043^{\mathrm{c}}$ \\
\hline Strontiumranelate & $1 / 7$ & $0 / 15$ & $0.161^{\mathrm{c}}$ \\
\hline New fractures yes/no & $3 / 5$ & $3 / 12$ & $0.363^{\mathrm{c}}$ \\
\hline Sports yes/no & $8 / 0$ & $8 / 7$ & $0.021^{\mathrm{c}}$ \\
\hline
\end{tabular}

*defined as a reduction on the NRS by 2 points. Data expressed as means \pm SD, $\pi$ independent $\mathrm{t}$ test, ${ }^{\mathrm{C}} \mathrm{Chi}$-square test

Worthy of note was the significant change in hand grip strength on the right side. Simultaneously, pain levels were reduced in patients who did the sports program regularly. We attribute this effect to the specificity of the component of strength; in other words, only those patients who perform specific exercises for muscle strength are able to increase their muscle strength. Some participants performed the muscle strengthening exercises regularly while others swam or biked.

The results of the present study reveal that, in addition to drug treatment for osteoporosis, consistent muscle exercises may be useful. In a meta-analysis of the impact of various physical activities on osteoporosis, many studies revealed an increase in bone density under regular physical activity. Moderately intensive exercises performed twice to four times a week, in short intervals and at a high frequency, appeared to be especially effective [28]. In the present study only five patients performed regular sports at baseline by way of intensive muscle exercises. Based on these results, patients should be advised to perform regular exercise. Sling therapy is a suitable option; among our patients this exercise led to a significant reduction of pain, improvement of physical fitness, and a positive perception of their subjective health [4].

Independent of drug therapy, a lower body weight with a normal BMI does appear to exert a positive effect on pain levels. In the group that achieved successful treatment, the probands were on average about $12.5 \mathrm{~kg}$ lighter and their BMI was markedly lower than the corresponding values in patients who did not achieve successful treatment. Segar et al. [29] showed that a high BMI is associated with pain, especially in the lower extremity; the authors also noted back pain in these patients.

\section{Conclusion}

- Teriparatide has - more than other drugs - a positive effect on the pain experienced by patients with osteoporosis.

- Independent of the perception of pain, drugs for osteoporosis have no impact on muscle strength.

- Physical activity or exercise in a sufficient dose does contribute to the reduction of pain in the long term among patients with osteoporosis.

- A normal BMI may influence the perception of pain in patients with osteoporosis.

- Supplementary muscle exercises aligned to the patient's level of fitness appear meaningful in addition to drug therapy.

\section{Limitations}

The prospective design and the limited size of the group are limitations of the present study. More complex statistical procedures could not be used. Thus, no general conclusions can be drawn on the basis of the present data. The absence of the blinding of patients and investigators is a further limitation. This is a single pilot study, so a misinterpretation of the findings is possible. Our results may not be generalizable. In general the investigation period of 18 months is short. Bisphosphonates partly unfold their effect up to 3 years. This permits limited statements about the long-term effects of the treatment. In future investigations we intend to evaluate the data of a longer period of intervention and thus achieve a better level of evidence.

\section{Declaration}

\section{Ethical Approval}

We declare that this study with human subjects is in accordance with the Helsinki Declaration of 1975 as amended in 2000 and that it has been approved by the competent institutional ethics committee of the University of Rostock (Trial registration No. A 2018-0247).

\section{Consent to participate}

All subjects were informed comprehensively about the methods, purposes and risks of the study protocol and also received a written declaration of informed consent.

\section{Consent for publication}

$\mathrm{BF}$ agreed in writing to the publication of the illustration. 


\section{Availability of data and material}

The vote of the Ethics Committee can be found at the following address (https: //www.ethik.med.uni-rostock.de/ A 2018-0247). The consent to the publication of the photographic material has been given to the journal.

\section{Authors' contribution}

HCS led the investigation and is co-responsible for the clinical trial concept. He also participated in the recruitment of the test subjects. GS designed the data preparation concept. UV carried out the survey, measurement and documentation of the data. RB participated in the data preparation and correction of the typesetting. VB was responsible for the translation of the journal article. AH carried out the statistical data evaluation.

\section{References}

1. Zanker J, Duque G (2018) Osteoporosis in Older Persons. Old and New Players. Journal of the American Geriatrics Society.

2. Bergland A, Thorsen H, Karesen R (2011) Effect of exercise on mobility, balance, and health-related quality of life in osteoporotic women with a history of vertebral fracture. A randomized, controlled trial. Osteoporosis international 22: 1863-1871.

3. Iwamoto J, Suzuki H, Tanaka K, et al. (2009) Preventative effect of exercise against falls in the elderly. A randomized controlled trial. Osteoporosis international 20: 1233-1240.

4. Schröder G, Knauerhase A, Kundt G, Schober H-C. 2012. Effects of physical therapy on quality of life in osteoporosis patients - a randomized clinical trial. Health and quality of life outcomes 10: 101.

5. Tella SH, Gallagher JC (2014) Prevention and treatment of postmenopausal osteoporosis. The Journal of steroid biochemistry and molecular biology 142: 155-170.

6. Reid IR, Horne AM, Mihov B, et al. (2018) Fracture Prevention with Zoledronate in Older Women with Osteopenia. The New England journal of medicine 379: 2407-2416.

7. Saag KG, Petersen J, Brandi ML, et al. (2017) Romosozumab or Alendronate for Fracture Prevention in Women with Osteoporosis. The New England journal of medicine 377: 1417-1427.

8. Guralnik JM, Ferrucci L, Simonsick EM, et al. (1995) Lower-extremity function in persons over the age of 70 years as a predictor of subsequent disability. The New England journal of medicine 332: 556-561.

9. Guralnik JM, Ferrucci L, Pieper CF, et al. (2000) Lower extremity function and subsequent disability. Consistency across studies, predictive models, and value of gait speed alone compared with the short physical performance battery. The journals of gerontology. Series A, Biological sciences and medical sciences 55: M221-31.

10. Guralnik JM, Simonsick EM, Ferrucci L, et al. (1994) A short physical performance battery assessing lower extremity function. Association with self-reported disability and prediction of mortality and nursing home admission. Journal of gerontology 49: M85-94.

11. Seefried L, Genest F (2017) Functional diagnostics of sarcopenia. Osteology 26: 13-17.

12. Cruz-Jentoft AJ, Bahat G, Bauer J, et al. (2018) Sarcopenia. Revised European consensus on definition and diagnosis. Age and ageing.

13. Runge M (2009) Fünf Esslinger. Ein Bewegungsprogramm für Muskel-KnochenFitness.

14. Rantanen T (2003) Muscle strength, disability and mortality. Scandinavian journal of medicine \& science in sports 13: 3-8.

15. Rantanen T, Volpato S, Ferrucci L, et al. (2003) Handgrip strength and causespecific and total mortality in older disabled women. Exploring the mechanism. Journal of the American Geriatrics Society 51: 636-641.

16. Basler HD (2011) Akutschmerztherapie in Pädiatrie und Geriatrie Schmerzmessung: Welche Schmerzskala bei welchen Patienten? Anästhesiol Intensivmed Notfallmed Schmerzther: 334-342.

17. Prince RL, Devine A, Dhaliwal SS, Dick IM (2006) Effects of calcium supplementation on clinical fracture and bone structure. Results of a 5-year, doubleblind, placebo-controlled trial in elderly women. Archives of internal medicine 166: 869-875

18. Bolland MJ, Avenell A, Baron JA, et al. (2010) Effect of calcium supplements on risk of myocardial infarction and cardiovascular events.Meta-analysis. BMJ (Clinical research ed.) 341: 3691.
19. Compston J, Cooper A, Cooper C, et al. (2017) UK clinical guideline for the prevention and treatment of osteoporosis. Archives of osteoporosis 12: 43.

20. Dimai HP (2005) Strontium ranelate. A novel concept for the treatment of osteoporosis. Wiener klinische Wochenschrift 117: 728-738.

21. Soen S, Fujiwara S, Takayanagi R, et al. (2017). Real-world effectiveness of daily teriparatide in Japanese patients with osteoporosis at high risk for fracture. Final results from the 24-month Japan Fracture Observational Study (JFOS). Current medical research and opinion 33: 2049-2056.

22. Genant HK, Halse J, Briney WG, et al. (2005) The effects of teriparatide on the incidence of back pain in postmenopausal women with osteoporosis. Current medical research and opinion 21: 1027-1034.

23. Odvina CV, Zerwekh JE, Rao DS, et al. 2005. Severely suppressed bone turnover. A potential complication of alendronate therapy. The Journal of clinical endocrinology and metabolism 90: 1294-1301.

24. Unnanuntana A, Saleh A, Mensah KA, et al. (2013) Atypical femoral fractures. What do we know about them?: AAOS Exhibit Selection. The Journal of bone and joint surgery 95: 1-13.

25. Ma C-M, Cheung M-H, Wong W-B (2015) Surgical Difficulties and Complications in the Treatment of Bisphosphonate-related Proximal Femur Fractures. 非典型股 骨近端骨折外科手術的困難和併發症. Journal of Orthopaedics, Trauma and Rehabilitation 19: 83-88.

26. Naito Y, Wakabayashi H, Kato S, et al. 2017. Alendronate inhibits hyperalgesia and suppresses neuropeptide markers of pain in a mouse model of osteoporosis. Journal of orthopaedic science 22: 771-777.

27. Ohishi T, Matsuyama Y (2018) Minodronate for the treatment of osteoporosis. Therapeutics and clinical risk management 14: 729-739.

28. Moreira LDF, Oliveira MLd, Lirani-Galvao AP, et al. (2014) Physical exercise and osteoporosis. Effects of different types of exercises on bone and physical function of postmenopausal women. Arquivosbrasileiros de endocrinologia e metabologia 58: $514-522$.

29. Segar AH, Urban JPG, Fairbank JCT, Judge A. 2016. The Association between Body Mass Index (BMI) and Back or Leg Pain in Patients with Spinal Conditions. Results from the Genodisc Study. Spine 41: 1237-E1243.

\section{Citation:}

Guido Schröder, Raimond Boldt, Anne Hornung, Verena Blaas Ulrike Voßmann, Hans-Christof Schober (2019) Impact of Drug-Based Treatment for Osteoporosis on Pain and Parameters of Physical Fitness - A Clinical Pilot Study. Integr J Orthop Traumatol Volume 2 (3): 1-8. 